\title{
Technical efficiency of chain sawmilling in Ogun State, southwest Nigeria
}

\author{
O. Y. OGUNSANWO ${ }^{1}$, I. G. ADELEYE ${ }^{1}$ and G. M. ANJAH ${ }^{2 *}$ \\ ${ }^{1}$ Department of Forest Resources Management, University of Ibadan, Nigeria. \\ ${ }^{2}$ Department of Plant Biology, University of Dschang, Cameroon. \\ * Corresponding author, E-mail: ngracemendi@yahoo.com; Tel.: +237 77539417
}

\begin{abstract}
Technical efficiency of chain sawmilling in terms of lumber recovery was examined in Ogun State, Nigeria. The data for this purpose were obtained from stump site wood converters otherwise known as artisanal sawyers in the State. Ninety logs from 17 families were sampled for the study. Influence of species density, saw kerfs thickness, log diameter as well as form factor on lumber recovery was examined using multiple and stepwise regression analyses. Result revealed that significant relationship exists between lumber recovery dependent variable and saw kerf thickness, log diameter, Log volume, and species density as independent variables. The study further revealed that Lumber Recovery Factor (LRF) ranges from $23.53 \%$ to $67.05 \%$ on individual $\log$ basis and a mean lumber recovery of $47 \%$ for all the sampled logs. Waste partitioning also revealed that the slabs proportion was $28.54 \%$ while sawdust and bark were $2.22 \%$ and $20.02 \%$ respectively. This study has provided a database on the efficiency of this small scale industry. Parameters such as log diameter, species density, log volume, saw kerfs thickness were found to be useful indices for predicting lumber recovery in artisanal sawing.
\end{abstract}

(c) 2011 International Formulae Group. All rights reserved.

Keywords: Lumber recovery, saw kerfs, species density, log diameter, sawnwood volume.

\section{INTRODUCTION}

In Nigeria and other countries like Cameroon and Ghana, forest based industries constitute one of the largest in the economy. The raw materials for wood industries, especially sawmilling come from the country's natural forest which represent $14.8 \%$ of the total forest (FAO, 2003). According to Owonubi and Badejo (2000) sawmilling is the most dominant and most active within the wood based industry, accounting for about $95 \%$ of the total wood input into the industry. However, in the last 10 years, Nigerian sawmills have witnessed a downward trend in their activities (FAO,
2003; Ogunsanwo et al., 2005), this is due largely to unutilized capacity as a result of power inefficiencies and obsolete machines. The trend and the ever increasing demand for sawnwood have paved way for illegal activities such as in-situ conversion to cushion the effect of inefficiencies in the saw milling industry.

Chain sawmilling or "flitching" as it is commonly called in Nigeria is a logging activity usually carried out in the forest by Artisanal sawyers' also known as mobile chain operators. It involves identification of trees with appropriate bole length to be felled, which are then felled with the use of mobile 
chain saw. These logs are then sawn into planks in-situ in the forest. This activity remains largely unauthorized and yet it is thriving.

In most cases, the activity takes place in difficult terrain when these "flitchers" seek permission from the forestry authorities to carry out this operation which is granted on the ground that they could help bring out these logs from the forest locations which are inaccessible to regular timber contractors. However, planks produced by "flitchers" are with rough surface and of low quality. This is due to the fact that sawing is hurriedly done as well as the crude method of sawing employed, occasioned by large and thick saw kerfs (Ogunsanwo et al., 2005). The products from artisanal sawing are primarily aimed at local market for the construction purposes; there has however been a proliferation of these products in the main urban centres across the country. This sector produces income and employment of labour and despite the danger posed; it is more or less completely beyond the control of the forestry administration (Rural Development Forestry Network, 2001). The operations are done without control and with low skill labour which lead to high wastage. Onchieku (2001) reported that sawn timber yield of farm grown Grevilla robusta in Meru district of Kenya compared the efficiency of unskilled and skilled power-saw and tractor-mounted saw bench operator shows that recovery rates ranged from $27 \%$ for unskilled power saw operators to nearly $60 \%$ for skilled saw bench operators. According to Pulki (1998), waste in this activities result from poor work method, felling and bucking technique. Despite the inefficiencies in this business, its contribution to both household and the national economy is quite significant. In Cameroon for instance, annual production (1998-99) in artisanal sector using chain saw was estimated at between $150,000 \mathrm{~m}^{3}$ and $200,000 \mathrm{~m}^{3}$ or nearly $700,000 \mathrm{~m}^{3}$ of $\operatorname{logs}$ which represent the equivalent of $27 \%$ to $36 \%$ of the amount produced by the modern sawmill (Rural Development Forestry Network, 2001).
However, the activities of the chain saw operators producing flitch remain illegal in most part of Nigeria. The illegality of this informal sector and the low technical efficiency in outputs thus requires that data be generated to investigate this conversion system. This study is therefore, initiated to assess the technical efficiency of artisanal sawing in Ogun State (Nigeria), with a view to determining the factors which could be manipulated for improved lumber recovery, and thus enhancing efficiency in the entire industry.

\section{MATERIALS AND METHODS Description of the study area}

This research was carried out in Ogun State, Nigeria. Ogun State has total land area of $17,084 \mathrm{~km}^{2}$ extending between Latitudes 60 30 and $795^{\prime} \mathrm{N}$ and longitude $2080 \mathrm{E}$ and 4 60 'E. It thus, lies in the south-western part of Nigeria. It is bound on the north by Oyo State, on the east by Ondo State and in the south by Lagos State as shown in Figure 1. Wood conversion was done in Idiroko, Obafemi and Ogbere as indicated in the map.

\section{Vegetation}

The distinct vegetation types in Ogun State are the low land rainforest found mostly in the southern part of the State, spreading across the State It is most extensive and thickest around Ogbere in Ijebu-East and it comprises of three tree layers which include upper, middle and lower stories. Savanna species such as Pakia biglobosa and Prosopis africana are found in the drier derived savanna zone of the study area. The other type of vegetation is riparian vegetation, which, where it is undisturbed, consists of considerably thick forest and swamps. The river basins in the area exhibit a somewhat higher natural fertility and support swamp vegetation. In the riparian forest zone, there are Chrysophyllum spp. Halea ciliata, Pentaclethra macrophylla, and Raphia hookeri. The lowland rainforest also consists mainly of species such as Albbiza zygia, Anthocleista spp, Aubrevillea kerestingii, 


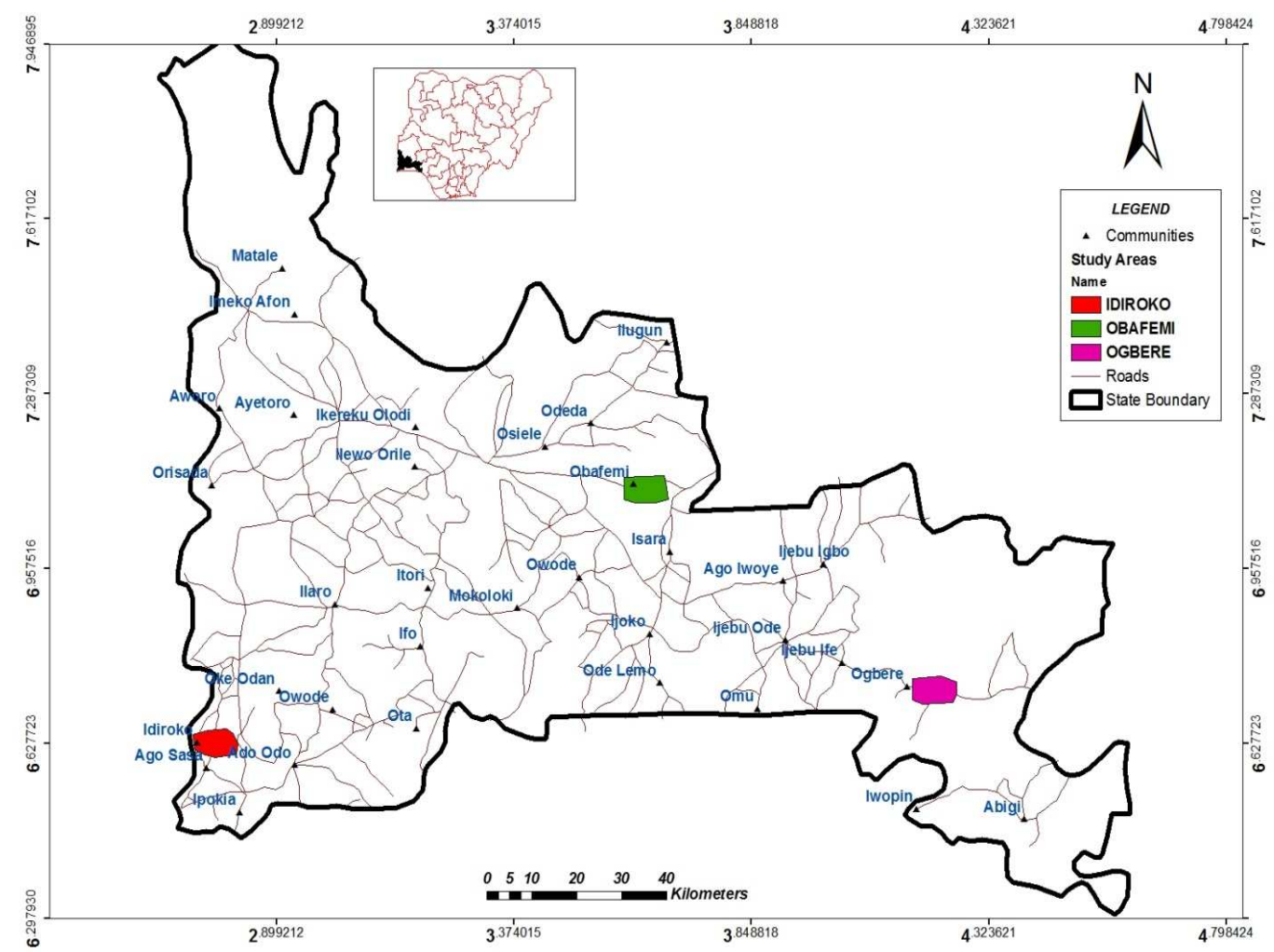

Figure 1: Map of Ogun State, Nigeria showing the study area.

Brachystegia spp., Canarium schweinfurthii, Ceiba pantandra, Celtis zenkeri, Milicia excelsa, Cola gingantea, Cordia platythyrsa, Khaya gradifoliola, Mansonia altissiama, Terminalia spp. and Triplochiton scleroxylon.

\section{Selection of materials}

\section{Reconnaissance survey}

A preliminary trip was embarked upon to visit the locations where artisanal sawing are predominantly practised in the State. Permission was obtained from Ogun State Ministry of Forestry for timber flitching in these locations which were not accessible for conventional logging system.

\section{Sampling procedure}

Ninety $\operatorname{logs}$ were sampled. Each $\log$ was measured at both butt and top for its diameter as well as under bark diameter. The $\log$ was then converted with the use of chainsaw and the numbers of the lumber pieces obtained there were then recorded. The procedure was repeated for all the ninety logs sampled as follows:

\section{Determination of lumber recovery (LR)}

The volume of log input was given by Basal Area $=\pi \frac{d^{2}}{4}$; Where $\mathrm{d}=$ Basal diameter The Actual Volume for each log was calculated from the formula

$V=\frac{h(A b+A u)}{2}$

$\mathrm{V}=h(A b+\mathrm{Au})$

Where: $\mathrm{V}=$ Volume of $\log ; \mathrm{h}=$ height of $\log /$ Length of log; $\quad \mathrm{Ab}=$ Cross sectional area at the base

$\mathrm{Au}=$ Cross Sectional area at the top.

Volume of sawn timber $\left(\mathrm{m}^{3}\right)$ 
$\mathrm{Vg}=\mathrm{L} \times \mathrm{T} \times \mathrm{W} ; \mathrm{Vg}=$ green volume of sawn timber; $\mathrm{L}=$ Length of Sawn timber in $\mathrm{M} ; \quad \mathrm{T}$ $=$ Thickness of Sawn timber in $\mathrm{m} ; \mathrm{W}=$ Width of Sawn timber in $\mathrm{m}$

\section{Determination of Lumber Recovery Factor (LRF)}

Lumber recovery factor $=$
$\frac{\Sigma v g}{V} \times 100$
$\mathrm{Vg}$

volume of sawn wood recovered $\times 100$

Where $\sum \mathrm{Vg}=$ Summation of volume of sawn timber.

\section{Woodwaste partitioning}

(a) Determination of volume of sawdust generated:

$\mathrm{SD}=\mathrm{L} \times \mathrm{W} \times \mathrm{K} \times \mathrm{T}$

Where SD = Saw dust

$\mathrm{L}=$ length in $\mathrm{m} ; \mathrm{W}=$ width $\mathrm{m} ; \mathrm{K}=$ kerf thickness; $\quad \mathrm{T}=$ thickness

(b). Volume of bark determination.

$$
\mathrm{V}_{\mathrm{B}}=\mathrm{V}-\mathrm{V}_{1}
$$

Where $\mathrm{V}_{\mathrm{B}}=$ Volume of Bark; $\mathrm{V}_{1}=$ Volume of log under bark

$\mathrm{V}=$ Volume of $\log$

(c) Determination of volume of Slabs;

$\mathrm{Vsl}=\mathrm{V}_{\mathrm{t}^{-}}\left(\mathrm{V}_{\mathrm{B}}+\mathrm{V}_{\mathrm{s}}\right)$

Where $\mathrm{V}_{\mathrm{sl}}=$ Volume of slab; $\mathrm{V}_{\mathrm{t}}=$ total $\log$ volume; $\mathrm{V}_{\mathrm{B}}=$ Volume of bark

$\mathrm{V}_{\mathrm{s}}=$ Volume of sawdust

Data obtained were analysed using descriptive statistics and ANOVA at 5\% level of significance. Also, Multiple Regressions was used to determine the influence of
(a) Log diameter on lumber recovery
(b) Kerf thickness on lumber recovery
(c) Density on lumber recover

\section{Determinants of lumber recovery}

Multiple Regressions was used to determine predictability of lumber recovery from selected variables. The model is given as $\mathrm{Y}=\mathrm{a}+\mathrm{b}_{1} \mathrm{X}_{1}+\mathrm{b}_{2} \mathrm{X}_{2}+\mathrm{b}_{3} \mathrm{X}_{3}+\mathrm{b}_{4} \mathrm{X}_{4}$
Where

$\mathrm{Y}=$ lumber recovery; $\mathrm{X}_{1}=$ Kerf thickness ;

$\mathrm{X}_{2}=\log$ diameter; $\mathrm{X}_{3}=$ density; $\mathrm{X}_{4}=\log$ diameter ratio

$\mathrm{a}, \mathrm{b} . . \mathrm{b} 4$ = Regression Coefficient (k).

\section{RESULTS}

Lumber recovery factor

Results showed that a total of 17 species were found to be commonly involved in chain sawmilling in the study area, three of these are in high density category, nine in medium density and 5 are found in the low density category, indicating that medium density woods are mostly converted in the practice. Lumber recovery (LR) in the study varied significantly according to density class at $5 \%$ level. High density species was $38.0 \pm 11.8$, medium density had $50.3 \pm 10.3$ while low density species was LR of $49.0 \pm$ as shown in Table 1. Table 2 presented lumber recovery by diameter class. It showed that logs with low diameter class of below $0.44 \mathrm{~m}$ had the lowest LR $38.1 \%$, while logs within 0.54 and 0.58 had the highest LR of $54.7 \%$. It is interesting to note that logs above $0.58 \mathrm{~m}$ diameter gave value which is slightly lower than the values obtained in 0.54-0.58 category, indicating that LR increases significantly to a maximum and decreased afterwards.

\section{Waste generation in chain sawmilling}

The result shows that chain sawmilling in the study area generates waste of $50.6 \%$ (Table 4), with $49.4 \pm 9.4 \%$ of sawn wood recovered. Bark was $20.0 \%$, sawdust $2.2 \%$ and slabs constitute $28.5 \%$. The waste generated is higher than $46.3 \%$ given by Egbewole et al. (2006) for conventional sawmilling.

\section{Relationships between lumber recovery and conversion parameters}

Correlation matrix for the relationships between lumber recovery and the independent variables are presented in Table 6. Basal and 
top diameters are significantly and positively correlated with lumber recovery while density, kerf size (Table 3) and form factor were negatively correlated.

Table 7 presents the contributions of the independent variables to LR in chain sawmilling. Basal diameter as a variable contributed $24 \%$ to lumber recovery, addition of top diameter to the model improved coefficient of determination to $44 \%$. It improved to $52 \%$ and $55 \%$ with addition of form factor and wood density respectively. The coefficient of determination was further improved to $57 \%$ when saw kerf was added to the model.

Table 1: Lumber recovery by log diameter class.

\begin{tabular}{lcc}
\hline Diameter Class & Mean Diameter & Lumber Recovery $(\boldsymbol{\%})$ \\
\hline Below 0.44 & $0.40 \pm 0.02$ & $38.1 \pm 09.8$ \\
$0.44-0.48$ & $0.47 \pm 0.01$ & $46.1 \pm 12.3$ \\
$0.49-0.53$ & $0.52 \pm 0.02$ & $52.0 \pm 06.6$ \\
$0.54-0.58$ & $0.57 \pm 0.02$ & $54.7 \pm 07.6$ \\
Above 0.58 & $0.62 \pm 0.03$ & $51.9 \pm 05.1$ \\
Mean & & $49.4 \pm 09.9$ \\
\hline
\end{tabular}

Table 2: Wood density classification and lumber recovery.

\begin{tabular}{|c|c|c|c|}
\hline Density class & Species & Density $\left(\mathrm{kgm}^{-3}\right)$ & Lumber Recovery (\%) \\
\hline \multirow[t]{3}{*}{ High } & Afzelia africana & 830 & $35.9 \pm 10.0$ \\
\hline & Celtis intergrifolia & 800 & $44.6 \pm 12.8$ \\
\hline & Millettia thoningii & 800 & $28.1 \pm 06.5$ \\
\hline \multicolumn{2}{|l|}{ Mean } & & $38.0 \pm 11.8$ \\
\hline \multirow{9}{*}{ Medium } & Terminalia superba & 560 & $51.8 \pm 08.6$ \\
\hline & Malacantha alnifolia & 496 & $60.5 \pm 03.4$ \\
\hline & Melicia excelsa & 660 & $61.9 \pm 02.7$ \\
\hline & Pycnanthus angolensis & 510 & $44.9 \pm 08.0$ \\
\hline & Piptadeniastrum africanum & 635 & $51.7 \pm 03.9$ \\
\hline & Terminalia ivorensis & 560 & $48.4 \pm 11.0$ \\
\hline & Hallea ciliata & 580 & $43.7 \pm 11.0$ \\
\hline & Entandrophragma utile & 660 & $45.4 \pm 10.1$ \\
\hline & Albizia zygia & 580 & $40.6 \pm 10.0$ \\
\hline Mean & & & $50.3 \pm 10.3$ \\
\hline \multirow{5}{*}{ Low } & Gmelina arborea & 480 & $48.5 \pm 07.3$ \\
\hline & Alstonia cogenesis & 400 & $59.8 \pm 03.8$ \\
\hline & Antiaris africana & 430 & $51.3 \pm 11.3$ \\
\hline & Cordia millenii & 480 & $48.3 \pm 05.5$ \\
\hline & Ceiba pentandra & 350 & $37.6 \pm 07.5$ \\
\hline Mean & & & $49.0 \pm 10.0$ \\
\hline
\end{tabular}


Table 3: Kerf thickness and lumber recovery.

\begin{tabular}{lll}
\hline Kerf thickness & Mean Lumber recovery & Standard Deviation \\
\hline $5 \mathrm{~mm}$ & 0.43 & \pm 0.102 \\
$4 \mathrm{~mm}$ & 0.53 & \pm 0.104 \\
\hline Degree of Freedom $=88(\mathrm{n}-2)$. & &
\end{tabular}

Table 4: Woodwaste expressed as percentage of total log input.

\begin{tabular}{lcccccc}
\hline & $\begin{array}{c}\text { Log Vol. } \\
\left(\mathbf{m}^{\mathbf{3}}\right)\end{array}$ & $\begin{array}{c}\text { Sawn } \\
\mathbf{w o o d} . \\
\left(\mathbf{m}^{\mathbf{3}}\right)\end{array}$ & $\begin{array}{c}\text { Waste. } \\
\left(\mathbf{m}^{\mathbf{3}}\right)\end{array}$ & Bark. $\left(\mathbf{m}^{\mathbf{3}}\right)$ & $\begin{array}{c}\text { Sawdust. } \\
\left(\mathbf{m}^{\mathbf{3}}\right)\end{array}$ & $\begin{array}{c}\text { Slabs } \\
\left(\mathbf{m}^{\mathbf{3}}\right)\end{array}$ \\
\hline Total & 63.84 & 31.41 & 32.43 & 12.78 & 1.42 & 18.22 \\
\hline $\begin{array}{l}\% \text { of } \log \\
\text { Volume }\end{array}$ & 100 & 49.40 & 50.60 & 20.02 & 2.22 & 28.54 \\
\hline
\end{tabular}

Table 5: Waste component as percentage of total waste in chain sawmilling and conventional sawmills in Nigeria.

\begin{tabular}{lcccc}
\hline Milling type & $\begin{array}{c}\text { Slab+ } \\
\text { sawdust }(\boldsymbol{\%})\end{array}$ & Bark (\%) & $\begin{array}{c}\text { Sawdust } \\
(\boldsymbol{\%})\end{array}$ & Slabs (\%) \\
\hline Conventional Sawmilling & 81.90 & 18.10 & 19.50 & 62.40 \\
Chain sawmilling & 60.36 & 39.4 & 4.18 & 56.18 \\
\hline Values for conventional sawmill estimated from Badejo and Giwa (1985).
\end{tabular}

Table 6: Correlation matrix between lumber recovery and log diameter, species density and sawkerf thickness.

\begin{tabular}{lllllll}
\hline Variables & $\begin{array}{l}\text { Lumber } \\
\text { Recovery }\end{array}$ & $\begin{array}{l}\text { Basal } \\
\text { Diameter } \\
\left(\mathbf{m}^{\mathbf{3}}\right)\end{array}$ & $\begin{array}{l}\text { Top } \\
\text { Diameter } \\
\left(\mathbf{m}^{\mathbf{3}}\right)\end{array}$ & $\begin{array}{l}\text { Form } \\
\text { factor }\end{array}$ & $\begin{array}{l}\text { Density } \\
\mathbf{K g m}\end{array}$ & $\begin{array}{l}\text { Kerf } \\
\text { Thickness } \\
(\mathbf{m m})\end{array}$ \\
\hline $\begin{array}{l}\text { Lumber } \\
\text { Recovery }\end{array}$ & 1.00 & & & & \\
\hline $\begin{array}{l}\text { Basal } \\
\text { Diameter }\end{array}$ & $0.49 *$ & 1.00 & & & \\
\hline $\begin{array}{l}\text { Top } \\
\text { Diameter }\end{array}$ & $0.45^{*}$ & $0.98 *$ & 1.00 & & \\
\hline Form factor & -0.12 & 0.14 & $0.32^{*}$ & 1.00 & & \\
\hline Density & $-0.32 *$ & -0.16 & -0.18 & -0.16 & 1.00 & \\
\hline Sawkerf & $-0.43 *$ & 0.03 & 0.07 & 0.19 & $0.23 *$ & \\
\hline$*$ Significant at $5 \%$ level of probability. & & & & & \\
\hline
\end{tabular}


Table 7: Stepwise regression results between Lumber recovery and independent variables.

\begin{tabular}{lll}
\hline Model Simple linear & S E & $\mathbf{R}^{2}$ \\
\hline (i) $\mathrm{Y}=0.44+84 \mathrm{x}_{1}$ & 0.99 & 0.24 \\
(ii) $\mathrm{Y}=0.496+0.866 \mathrm{x}_{1}-0.102 \mathrm{x}_{2}$ & 0.086 & 0.44 \\
(iii) $\mathrm{Y}=-0.489+4.68 \mathrm{x}_{1}-0.97 \mathrm{x}_{2}-1.38 \mathrm{x}_{3}$ & 0.080 & 0.52 \\
(iv) $\mathrm{Y}=-0.47+4.91 \mathrm{x}_{1}-0.087 \mathrm{x}_{2}-1.48 \mathrm{x}_{3}-0.0002 \mathrm{x}_{4}$ & 0.078 & 0.55 \\
(v) $\mathrm{Y}=-2.21+7.57 \mathrm{x}_{1}-0.96 \mathrm{x}_{2}-2.46 \mathrm{x}_{3}-0.0002 \mathrm{x}_{4}+1.18 \mathrm{x}_{5}$ & 0.077 & 0.57 \\
\hline
\end{tabular}

\section{DISCUSSION}

The 17 species identified in the study are the ones that are commonly used in this practice. Given the species diversity in tropical forest environment, the few species indentified in this study are likely to have been demand driven as identified in the work of Bui et al. (2005). It should be noted that choice species like Afzelia Africana, Terminalia superb, Terminalia ivorensis, Milicia exelsa, Entandrophragma utile and Cordia millenii are sawn. Other species like Gmelina arborea, Alstonia cogenesis, Albizia zygia, Malacantha alnifolia and Celtis intergrifolia. The practice has thus become an avenue for emergence of lesser-used species which could constitute viable alternatives for high valued timber species which are normally sort after. Efficiency in the industry should therefore, among other things, harmonize list of species used with those of other Lesser-Known Species LKS with a view to strategizing effective marketing for overall sustainability in the forest-based industry.

On individual species basis, LR ranged between $28.1 \pm 0.6 \%$ and $61.9 \pm 2.7 \%$ with overall mean of $49.4 \pm 9.4 \%$. This is similar to the report given by Udoh (1994) where chain sawmilling in Cross River State, Nigeria, was estimated at $46 \%$. Also, Onchieku (2001) reported that recovery rates ranged from $27 \%$ for unskilled power-saw operators to nearly $60 \%$ for skilled bench saw operators. Unlike conventional sawmill where lumber recovery was estimated to be 53.7\% Egbewole (2006), lumber recovery in chain sawmilling is generally low due to several factors ranging from large kerf size to size of log converted. According to Pasiecznik et al. (2006), most
Chainsaw milling today are carried out 'freehand', that is without the use of any guide, frames or rails that would otherwise help sawyers produce better quality boards with less chance of accidents.

Influence on $\log$ diameter on lumber recovery is well established in this study. The result is in tandem with earlier reports (Wang et al., 2003; Egbewole et al., 2006) where Lumber recovery in Taiwania cryptomeriodes and some high forest tropical hardwoods were found to increase linearly with increase in dbh. In this study however, a tree in the diameter category $>0.58 \mathrm{~m}$ was slightly lower in LR than in diameter class $0.54-0.58$. This could mean that large logs are at advanced age and as such contain large volumes of defects which may affect the ultimate recovery from such logs. The scope of the present study is however outside the use of the influence of defects such as knots and heart rots as parameters for lumber recovery. Research in the future should involve these and other parameters which are not covered in the present study.

Although influence of wood density on conversion efficiency has not been well documented in chainsaw milling, however, difficulties encountered in converting high density wood at this level of sawmilling might be responsible for the low recovery obtained in high density timber as found in this study.

Volume recovery by sawkerf thickness shows that higher recovery of $0.53 \mathrm{~m}^{3}$ was obtained in $4 \mathrm{~mm}$ kerf while the $5 \mathrm{~mm}$ kerf produced lower lumber recovery of $0.43 \mathrm{~m}^{3}$ as in Table 3. In conventional sawmilling, effect of saw kerf reduction on LR are well documented (Steele, 1984; Kuenzi, 2002). 
According to Steele (1984), more lumber recovery is achieved both by obtaining extra boards as well as wider board from the log as a result of reduction in saw kerf. Effect of saw kerf on lumber volume recovery in chain sawmilling is not well documented from empirical findings, available reports have however attributed enormous waste usually encountered in artisanal sawing to the thickness of the saw blade used among other reasons. The driving factor in the chain sawmilling sub-sector in the study area is the demand by the local market mainly for building and associated uses with little or no regard for standard product specification. According to Steele (1984), the decision of sawmill personnel significantly affect lumber recovery. The heterogeneous nature of the raw material demands that machine operators make thousand of decisions every day. In conventional sawmills, decision making may be easier, unlike in chain sawmilling where multiple decisions especially on the first line of cut with respect to the shape of the log is very crucial, usually, the conversion of $\log$ is hurriedly executed so that they are not caught in the process for those who operate illegally.

An analysis of waste components shows that slab constitutes the bulk of waste generated for both conventional and chainsaw milling Table 5. The proportion of slab in conventional sawmilling $(62.4 \%)$ is however higher than that of chainsaw milling $(56.2 \%)$. Also, the proportion of sawdust was $4.18 \%$, which is higher than the value obtained by Badejo and Giwa (1985). The reason for this observation may not be farfetched. In conventional sawmilling, there are ample opportunities for converting logs into various dimensions, which may lead to generation of more sawdust. Chainsaw milling as presently practiced in the study area is largely illegal; conversion of $\operatorname{logs}$ is mainly into larger dimensions. This is due to many factors such as cost of inputs like fuel, the need to convert as many logs as possible before day break for fear of being apprehended by forestry personnel is also a contributory factor to this.
It is important to note the significant relationship between lumber recovery and saw kerf thickness in this study. Chainsaw milling is characterized with high kerf loss as a result of the large size of the saw used in the practice. The result of the T-test carried out on the means and lumber recovery of the two saw types used in this study was presented. It was observed that thinner kerf of $4 \mathrm{~mm}$ have highest mean lumber recovery of 0.53 . Thus, thin Kerf sawing will enable the use of lower quality and/or smaller diameter logs which otherwise may have little or no economic value. Consequently, forest management could be stimulated to improve and expand the resource base and lead to more successful rural development efforts in retaining, expanding, and attracting wood-using industries.

The place of research in chainsaw milling as at today is to find ways of adding gadgets to chainsaws in order to improve on the straightness and surface quality of sawnwood produced from chainsaw milling. Reducing the saw kerf in chain sawmilling may not be feasible for now. It may therefore not be out of place to recommend larger dimension sawnwood for chainsaw milling as a strategy for reducing waste in the industry.

\section{REFERENCES}

Badejo SO, Giwa GA. 1985. Volume assessment and economic importance of wood Wastes utilisation of Nigeria. Technical report no. 50, Forestry Research Institute of Nigeria, Ibadan.

Bui HB, Harrison S, Lamb D, Brown SM. 2005. An evaluation of the small-scale sawmilling and timber processing Industry in northern Vietnam and the need for planting particular indigenous species. Small-scale Forest Economics, Management and Policy, 4(1): 85-100.

Egbewole ZT, Afuwape MA, Ogunsanwo OY. 2006: Lumber recovery from high forest tree species in selected sawmills of south-western Nigeria. Bowen Journal of Agriculture, 3(2): 151-162. 
FAO. 2003. Forestry outlook study for Africa: Sub regional report - West Africa. FAO; $65 \mathrm{pp}$.

Kuenzi T. 2002. The Effects of Wane Allowance, Kerf and Target Size Reduction on Sawmill Optimization research report submitted to: Jim Funck and Jeff Morrell FP 413 Senior Project Report June 5, 2002 Pp 29.

Ogunsanwo OY, Aiyeloja AA, Filani GS. 2005. Assessment of off-site waste associated with timber flitching in Ibadan. In proceedings of $30^{\text {th }}$ Annual Conference of Forestry Association of Nigeria (FAN). Pp 345-353.

Onchieku J. 2001. Assessment of sawn timber yields (recovery rates) of G. robusta from farmlands in Meru Central District, Kenya. Report, ICRAF/FAN timber marketing Project.

Pasiecznik NM, Brewerr MCM, Fehrc, Samuel JH. 2006. In Turning Trees to Timber; A Chainsaw Milling Manual. HDRA Conventry, UK 339pp. http:///chainsaw.gwork.org

Pulki RE. 1998. Conventional versus environmentally sound harvesting; impacts on non-coniferous tropical veneer logs and sawlogs. Unasylva 4903 Richardson (1976).

Rural Development Forestry Network (RDFN). 2001. Small scale logging in community forest in Cameroun; Towards ecologically more suitable and socially more acceptable compromises. pp 5-11

Owonubi JJ, Sadejo SOO. 2000. New trends in cement-board research for plywood manufacture at Forestry Research Institute of Nigeria FRIN, Ibadan. Nigeria. Proceedings of Conference on Enterprises, University of Benin, Nigeria pp 2.

Song YW, Cheng JL, Chih MC. 2003. Effect of thining and pruning on knots and lumber recovery of Taiwania (Taiwania cryptomerioides) planted in the Lu-Kuei area. Journal of Wood Science (49): 444 449.

Steele H. 1984. Factors determining lumber recovery in sawmilling. Gen. Tech. Rep. FPL-39. Madison, WI: U.S. Department of Agriculture, Forest Service, Forest Products Laboratory, 1984. 8pp.

TRADA. 1979. Timber of the world. Pub. Longman Inc.: New York; 463p.

Udo ES. 1994. Profitability of producing sawnwood with portable chainsaw in Cross River State. Nigerian Journal of Forestry, 24/25: 31-35. 